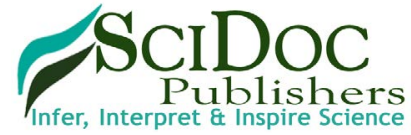

\section{Spectacular Presentation of Tuberous Xanthomas in a Case of Familial Hypercholesterolemia Type IIa}

\section{International Journal of Pediatric Health Care \& Advancements (IJPA) ISSN 2572-7354}

Barbach Y*, Chaouche M, Cherif AD, Elloudi S, Baybay H, Mernissi FZ

Dermatology Department, University Hospital Hassan II, Morocco.

Abstract

Xanthomas are localized lipid deposits within organs that may manifest as papules, plaques, or nodules in skin. The subtype of xanthoma provides a clue to the underlying lipid abnormality. Accurate diagnosis of xanthomas is important because it can lead to the identification and treatment of underlying disease. Xanthomas associated with familial hypercholesterolemia are an exception. In patients with this disorder they often begin to develop prior to the age of 10 years. We report a case of 16-year-old child suffering from a spectacular form related to homozygous familial hypercholesterolemia.

Keywords: Xanthomas; Lipid disorders; Familial Hypercholesterolemia.

\section{Introduction}

Xanthomas are benign lesions that may manifest as papules or nodules in skin, characterized by the accumulation of lipids on macrophages that develop in the subcutaneous tissue [1]. Tuberous xanthomas are yellow or red, firms nodules, most commonly seen on the extensor members of the limbs and buttocks [2]. They are observed in several lipidoses and generally indicate a trouble of lipoprotein metabolism, in particular familial hypercholesterolemia, and generally do not exceed $2 \mathrm{~cm} \mathrm{[3].}$

\section{Case Report}

16 year old child, who had from early childhood papular yellowish lesions that progressively increased in the hands, elbows, knees and ankles without other cutaneous or systemic signs. His parents were cousins of the 1 st degree. A similar case found with his brother, who died at the age of 18. The dermatological examination revealed the presence of multiple papulo-nodular and tumoral yellowish lesions, with variable size, rounded, confluent in places, with hilly surface in places, painless, symmetrical, at the level of the EID, EIP, knees, heels and elbows [Figures 1-23]. Cutaneous biopsy showed the presence of numerous foamy histiocytes isolated or grouped into clusters [Figures 4-5].
The lipid profile showed very high levels of total cholesterol (7.96 g/L), LDL-cholesterol (6.95 g/L), HDL cholesterol was decreased $(0.78 \mathrm{~g} / \mathrm{L})$. The child was treated with diet and lifestyle measures associated with statin therapy (simvastatin $20 \mathrm{mg} /$ day). Surgical treatment for troublesome tumors on the elbows.

\section{Discussion}

Xanthomas are cutaneous markers of the underlying disorders of lipid metabolism, classified by Frederickson into five classes. Tuberous xanthomas are generally found in familial hypercholesterolaemia type IIa [3, 4]. Familial hypercholesterolemia is an autosomal codominant disorder with elevated LDL levels due to increased production and reduced resorption of LDL secondary to dysfunctional LDL receptors. Heterozygotes express half the number of LDL receptors and homozygotes have between $0 \%$ and $25 \%$ [5].

The homozygous form is characterized by early cutaneous and vascular manifestations related to cholesterol deposition [1]. The cutaneous manifestations are tuberous xanthomas, which are very characteristic lesions, firm, nodular or pseudo-tumoral, painless, yellow or orange, measuring between 0.5 and $3 \mathrm{~cm}$ in diameter,

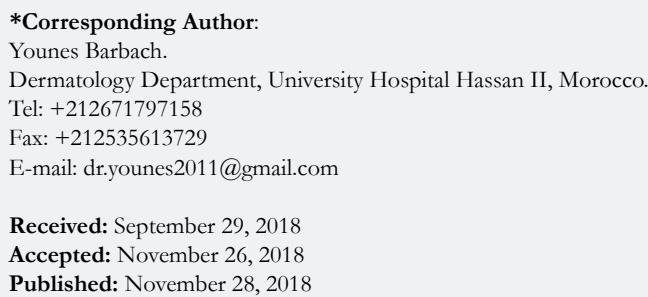

Copyright: Barbach $\mathbf{Y}^{\odot}$ 2018. This is an open-access article distributed under the terms of the Creative Commons Attribution License, which permits unrestricted use, distribution and reproduction in any medium, provided the original author and source are credited. 
Figures 1-5. Multiple Giant tuberous and plane xanthomas.
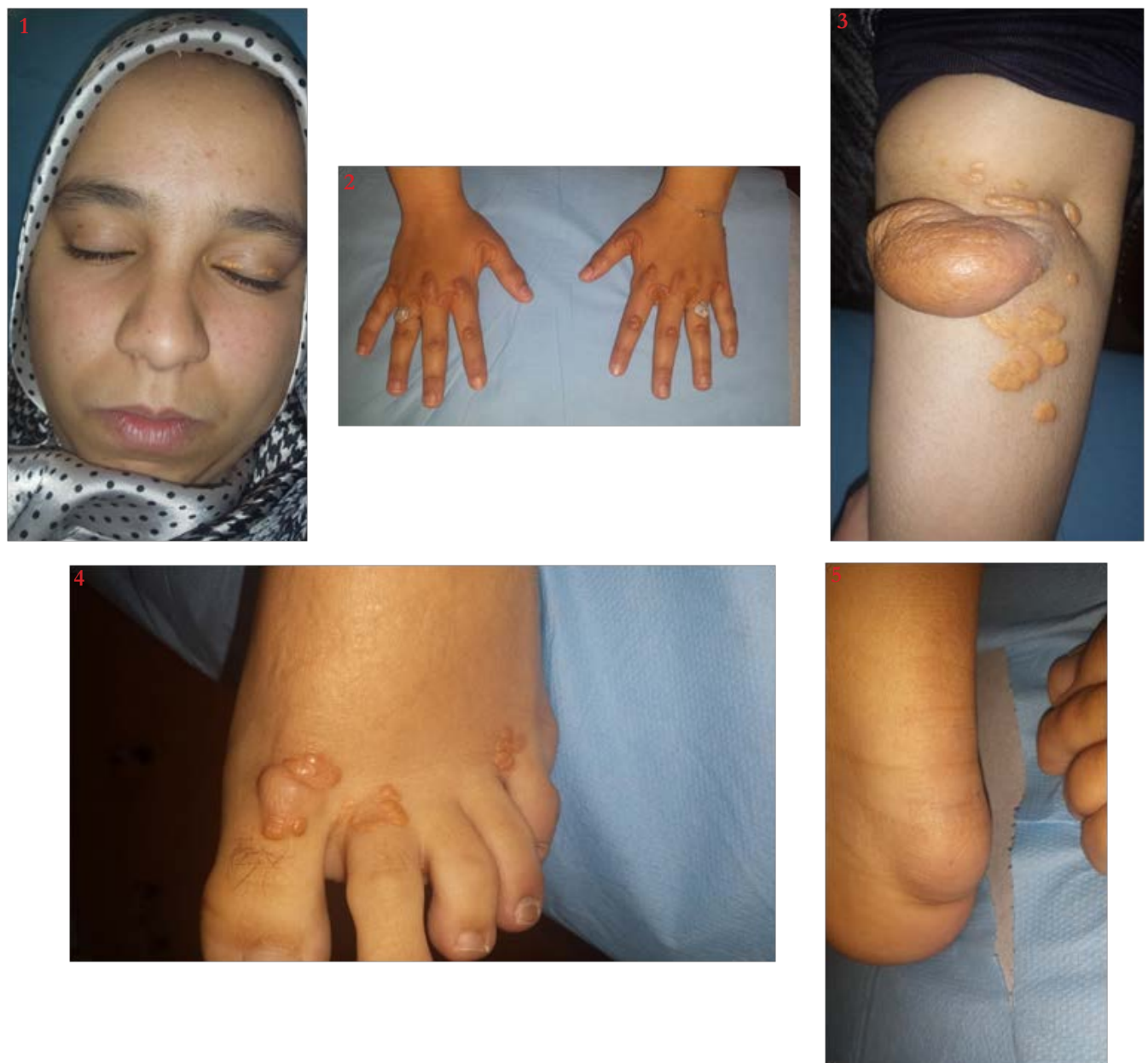

Figures A-B. Histological images: presence of numerous histiocytes with abundant foamy cytoplasm, rich in lipid vacuoles.

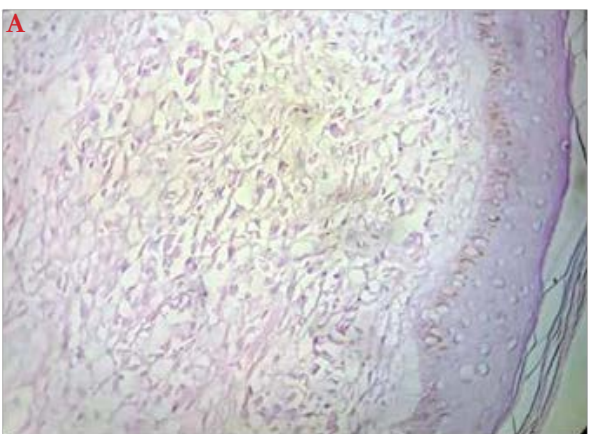

mainly sitting on the gluteal region, and the extension face of the elbows and knees. Planar xanthomas can associate with it, of orange-yellow aspect, particularly visible at the level of the buttocks, folds of the articulations but can form true sheets of several square centimeters. The appearance of these xanthomas is all the more precocious as the hypercholesterolemia is severe and they can exist from birth [6].

Biologically, the homozygous form is characterized by very high total cholesterol levels at birth (6 to $15 \mathrm{~g} / \mathrm{L}$ ), as well as LDLcholesterol and apoprotein B. There is usually an associated hypoHDLemia. Triglyceride concentrations are normal.

The main complications are cardiac, more rarely cerebral, vascular and peripheral arterial. There is a correlation between the level

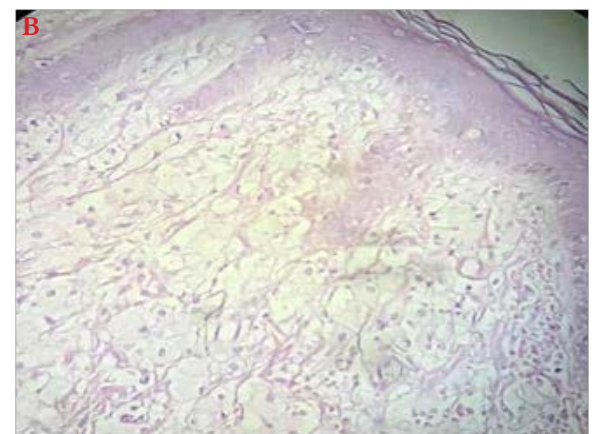

of hypercholesterolemia and the age of onset of atherosclerotic complications, indeed, the homozygous form achieves at most a true experimental atheromatosis characterized by a significant invasion of the aortic root by cholesterol deposits realizing supravalvular stenosis often calcified and rapidly progressive [7]. This truly malignant atherosclerosis can include coronary ostia. The risk is sudden death by massive infarction. On average, the first angina attack occurs around the age of 11, and life expectancy does not exceed 20 years without treatment $[8,9]$. The therapeutic management of homozygous hypercholesterolemia, because of its rarity, its specificity and its serious prognosis, is conceived only in very specialized services.

The treatment of choice for this form is LDL-apheresis : selective $+/$ - purification of LDLs. It must be performed at the age when 
the blood volume allows the realization of extracorporeal blood circulation. In combination with LDL-apheresis, statins have shown efficacy [9].

\section{Conclusion}

We report a case of familial hypercholesterolemia type IIa in a context of consanguinity as described previously. The shortage of specialized centers of LDL-apheresis in our country explains that our care has remained insufficient, allowing only a slight decrease in total cholesterol and LDL cholesterol.

\section{References}

[1]. Rachadi H, Ramli I, Amarouch H, Bouhalab J, Berbich L, Senouci K, et al. Tuberous Xanthomas presenting spectacularly revealing homozygous familial hypercholesterolemia. Ann Dermatol Venereol. 2014 Dec 1;141(12):S382.

[2]. Mohan KK, Kumar KD, Ramachandra BV. Tuberous xanthomas in type IIA hyperlipoproteinemia. Indian J Dermatol Venereol Leprol. 2002 MarApr;68(2):105-6. PubMed PMID: 17656897.
[3]. Cruz PD Jr, East C, Bergstresser PR. Dermal, subcutaneous, and tendon xanthomas: diagnostic markers for specific lipoprotein disorders. J Am Acad Dermatol. 1988 Jul;19(1 Pt 1):95-111. PubMed PMID: 3042820.

[4]. Vermeer BJ, Gevers Leuven J. New aspects of xanthomatosis and hyperlipoproteinemia. Curr Probl Dermatol. 1991;20:63-72. PubMed PMID: 1935220.

[5]. Austin MA, Hutter CM, Zimmern RL, Humphries SE. Familial hypercholesterolemia and coronary heart disease: a HuGE association review. Am J Epidemiol. 2004 Sep 1;160(5):421-9. PubMed PMID: 15321838.

[6]. Bhagwat PV, Tophakhane RS, Kudligi C, Noronha TM, Thirunavukkarasu A. Familial combined hypercholesterolemia type II b presenting with tuberous xanthoma, tendinous xanthoma and pityriasis rubra pilaris-like lesions. Indian J Dermatol Venereol Leprol. 2010 May-Jun;76(3):293-6. doi: 10.4103/0378-6323.62988. PubMed PMID: 20445310.

[7]. Morrisett JD, Vickers KC. Vascular calcification in homozygote familial hypercholesterolemia. Arterioscler Thromb Vasc Biol. 2008 Apr;28(4):606-7. doi: 10.1161/ATVBAHA.108.163378.

[8]. Hopkins PN. Familial hypercholesterolemia--improving treatment and meeting guidelines. Int J Cardiol. 2003 May;89(1):13-23. PubMed PMID: 12727001.

[9]. Moga C, Harstall C. Low density lipoprotein apheresis for the treatment of familial hypercholesterolemia. Alberta Heritage Foundation for Medical Research; 2004 Apr. 